Post-print version of 'Jato-Espino, D., Yiwo, E., Rodriguez-Hernandez, J., Canteras-Jordana, J.C. (2018). "Design and application of a Sustainable Urban Surface Rating System (SURSIST)”. Ecol. Indic., 93: 1253-1263. DOI: 10.1016/j.ecolind.2018.06.022'. 



\section{Design and application of a Sustainable Urban Surface}

2 Rating System (SURSIST)

4 Daniel Jato-Espino ${ }^{\mathrm{a}, *}$; Ebenezer Yiwo ${ }^{\mathrm{a}}$; Jorge Rodriguez-Hernandez ${ }^{\mathrm{a}}$; Juan Carlos

5 Canteras-Jordana ${ }^{b}$

${ }^{a}$ GITECO Research Group, Universidad de Cantabria, Av. de los Castros 44, 39005, Santander, Spain

${ }^{b}$ Ecology Research Group, Department of Water and Environmental Sciences and Techniques, Universidad de Cantabria, Av. de los Castros 44, 39005, Santander, Spain

E-mail addresses: jatod@unican.es (D.Jato-Espino); me.joe22@yahoo.com (E. Yiwo); rodrighj@unican.es (J.Rodriguez-Hernandez); canteraj@unican.es (J.C. Canteras-Jordana

* Corresponding author. Tel.: +34 942203943; Fax: +34 942201703.

\section{Abstract}

Urban surfaces reflect the economic, environmental and social idiosyncrasy of cities, playing a crucial role in the sustainable development of modern civilizations. Thus, the planning and efficient management of the skin of urban areas provides an opportunity to facilitate the fulfilment of the needs of present and future generations. However, there is a lack of specific tools to evaluate the contribution of these surfaces to achieving the Sustainable Development Goals (SDGs), which is the current framework adopted by the United Nations to measure progress towards sustainability. Consequently, this paper describes the design and application of a Sustainable Urban Surface Rating System (SURSIST) aimed at producing a composite sustainability index to measure the contribution of the land cover of entire cities to meeting the SDGs. SURSIST was based on a series of indicators proposed in accordance to the targets forming the SDGs, which were processed by combining CORINE Land Cover (CLC) maps with the Analytic Hierarchy Process (AHP) and the Technique for Order of Preference by Similarity to Ideal Solution (TOPSIS). The application of SURSIST to the Spanish cities of Santander and Valencia during the time period from 1990 to 2006 demonstrated the progressive decrease in sustainability experienced by their urban surfaces due to the increased presence of impermeable covers. The replacement of a moderate part of the built-up area present in both cities in 2006 by greenspace proved to be a solution for recovering the degree of sustainability lost from 1990. 
Land cover; Rating system; Sustainability Indicators; Sustainable Development Goals; Urban planning; Urban surfaces

\section{Introduction}

The increasing trend in world population, which is forecasted to grow up to 9 billion in 2050 (UNEP, 2012), is entailing changes in the urban skin of cities as a result of humanrelated activities. About $70 \%$ of this increased population is expected to live in urban areas by 2050 (Tucci, 2001), producing alterations in land covers, which are progressively evolving from natural spaces to built-up surfaces to satisfy human needs and consumption habits. This process is favoring the depletion of natural resources, as well as the disposal of waste required for producing goods and services to the air, land and water. In the end, these circumstances endanger meeting the objectives of sustainable development, which seek to fulfil the needs of future generations.

The principles established in the United Nations Conference on Sustainable Development (Rio+20), which crystallized in the Sustainable Development Goals (SDGs), highlighted that human developments must harmonize economic growth, environmental protection and social inclusion (Diaz-Sarachaga et al., 2017). The consideration of sustainability plays a key role in balancing the variety of factors involved in the path towards urban progress. The adoption of equitable approaches is crucial, since developed areas are hotspots in terms of resource consumption, waste and pollution generation, environmental degradation and social inequality. Addressing all these issues requires comprehensive urban planning and design strategies to ensure quality of life in cities.

In this context, the concept of sustainable rating system emerged as a set of indicators to evaluate sustainability through the scoring of a series of best practices (Hart, 2006). One of the main virtues of these systems is their capability to jointly assess a wide variety of different indicators, regardless of the units in which they are measured $\left(€, \mathrm{~kg} \mathrm{CO}_{2}, \mathrm{~m}^{3}\right.$, linguistic scores, etc.). The application of sustainable rating systems enables determining overall indices revealing the degree of sustainability achieved, for which they might use a series of theoretical methods related to the branch of operations research (Singh et al., 2007).

The development of sustainable rating systems initially focused on the assessment of buildings and infrastructures. Rating tools for buildings emerged more than twenty years ago (Häkkinen, 2007) in the form of the following systems: Building Research Establishment Environmental Assessment Method (BREEAM), Comprehensive Assessment System for Building Environmental Efficiency (CASBEE) and Leadership in Energy and Environmental Design (LEED). The acceptance of these tools led to the development of other rating systems for evaluating major infrastructures, such as Civil Engineering Environmental Quality (CEEQUAL), ENVISION and Infrastructure Sustainability (IS) Rating Tool (Diaz-Sarachaga et al., 2016). Diaz-Sarachaga et al. (2017) recently developed 
103

104

105

106

107

108

109

110

111

112

113

114

115

a new Sustainable Infrastructure Rating System for Developing Countries (SIRSDEC) based on the consideration of the Millennium Development Goals (MDGs), which expired in 2015 and were superseded by the SDGs.

Some of the aforementioned rating systems evolved to provide specific frameworks for assessing the degree of sustainability of urban developments, especially ENVISION and LEED, which has released up to three different versions related to this matter (Neighbourhood Development, Cities and Communities). However, there is a lack of ad-hoc tools aimed at measuring the contribution of urban surfaces to sustainable development. Some efforts have been undertaken to explore the implications of LULC changes for sustainability (Hassan and Nazem, 2016; Li et al., 2001; Mwavu and Witkowski, 2008) and ecosystem services (García-Nieto et al., 2018; Santos et al., 2018; Zhou et al., 2017), but these studies do not provide a rating system for measuring how the land cover of a city contributes to the SDGs over time either.

As a result of all these considerations, the aim of this research was to develop a Sustainable Urban Surface Rating System (SURSIST) to determine the extent to which the land cover configuration of a city contributed to sustainability. To this end, a list of indicators aligned with the specific targets to be met in the SDGs was proposed to evaluate urban surfaces in terms of sustainable development. The sequential processing of these indicators yielded a composite score indicating the degree of sustainability of the urban skin of a city. The usefulness of SURSIST was tested through two different case studies corresponding to Santander and Valencia (Spain), which provided evidence of the reduction in sustainability experienced by the land cover of both cities over time and the opportunity represented by greenspace to bring it back.

\section{Methodology}

The design of the Sustainable Urban Surface Rating System (SURSIST) was carried out as a sequence of steps as represented in Fig. 1. The first phase consisted of conceiving a list of indicators representing the potential contribution of urban surfaces to sustainability, based on the Sustainable Development Goals (SDGs). Then, these indicators were characterized and weighted with the support of the CORINE Land Cover (CLC) project and the Analytic Hierarchy Process (AHP), respectively. The last step concerned the creation of a composite index to measure the overall contribution of the urban skin of a city to achieve the SDGs using the Technique for Order of Preference by Similarity to Ideal Solution (TOPSIS). 

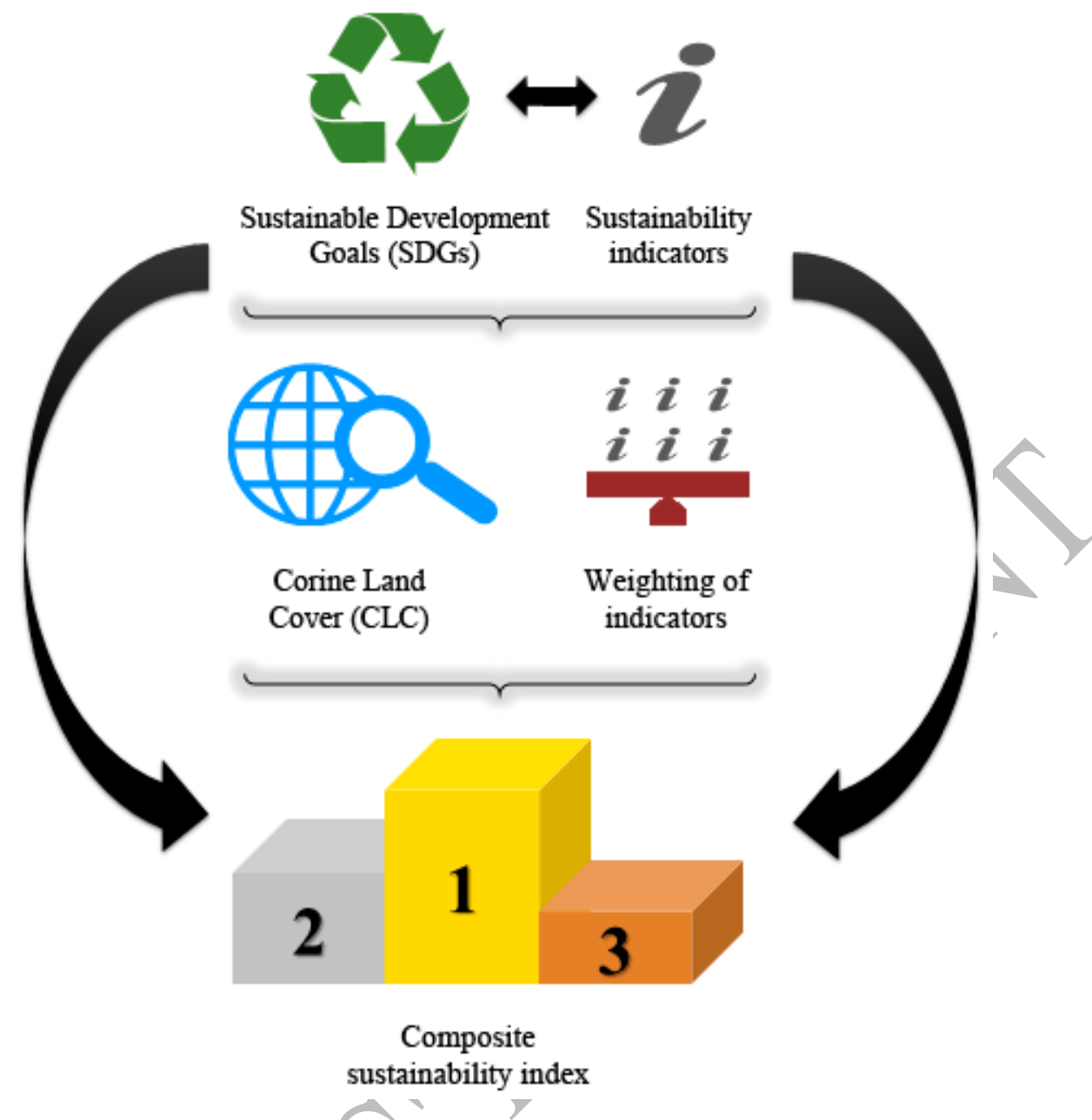

Fig. 1. Outline of the proposed methodology for the development of the Sustainable Urban Surface Rating System (SURSIST)

\subsection{Sustainable Development Goals (SDGs)}

The SDGs, which were approved in the United Nations Conference on Sustainable Development held in Río de Janeiro in 2012 (UN-DESA, 2012), emerged to promote the implementation of actions for fulfilling several objectives related to the sustainability of people and the planet over the next years. The involvement of all countries and relevant stakeholders is crucial for ensuring the achievement of the SDGs, whose main lines of action are as follows:

- End of poverty, hunger and gender inequalities, with a focus on protecting human health and ensuring the welfare of people.

- Mitigation of impacts caused by Climate Change to safeguard air, land, water and biodiversity from degradation.

- Efficient management of natural resources and implementation of responsible production and consumption practices.

- Promotion of the prosperity of people through peaceful and inclusive societies, decent work and economic growth. 
136 The New Urban Agenda adopted in the United Nations Conference on Housing and 137 Sustainable Urban Development (Habitat III) (UN, 2016) pointed out to sustainable urban 138 development as a trigger for global sustainable development. The skin of urban spaces 139 plays an essential role in the sustainability of cities, since it strongly influences their de140 gree of development and environmental, economic and social condition. Table 1 shows a 141 list of targets included in the United Nations SDGs, which were suggested due to their 142 close relationship to the planning of urban land cover. According to Table 1, the efficient 143 management of the surfaces of a city can contribute to achieving up to 18 targets grouped 144 into 12 SDGs.

145 This fact highlighted the need for designing a rating system for translating the links 146 between the urban skin and the SDGs into a semi-quantitative measure of the degree of 147 sustainability of a whole city in terms of its land cover. Due to its orientation to the SDGs, 148 the creation of such system can be very helpful in monitoring the fulfilment of the chal149 lenges posed by the United Nations to ensure leaving a better planet for future genera150 tions. 
Sustainable Development Goal (SDG)

1 No Poverty

2 Zero Hunger

3 Good Health and Well-being

$6 \quad$ Clean Water and Sanitation
Target

5 By 2030, build the resilience of the poor and those in vulnerable situations and reduce their exposure and vulnerability to climaterelated extreme events and other economic, social and environmental shocks and disasters

3 By 2030, double the agricultural productivity and incomes of small-scale food producers, in particular women, indigenous peoples, family farmers, pastoralists and fishers [...]

6 By 2020, halve the number of global deaths and injuries from road traffic accidents

9 By 2030, substantially reduce the number of deaths and illnesses from hazardous chemicals and air, water and soil pollution [...]

3 By 2030, improve water quality by reducing pollution, eliminating dumping and minimizing release of hazardous chemicals and materials, halving the proportion of untreated wastewater and substantially increasing recycling and safe reuse globally

4 By 2030, substantially increase water-use efficiency across all sectors and ensure sustainable withdrawals and supply of freshwater to address water scarcity and substantially reduce the number of people suffering from water scarcity

$7 \quad$ Affordable and Clean Energy

3 By 2030, double the global rate of improvement in energy efficiency

8 Decent Work and Economic Growth

4 Improve progressively, through 2030, global resource efficiency in consumption and production and endeavour to decouple economic growth from environmental degradation [...]

9 Industry, Innovation and Infrastructure

1 Develop quality, reliable, sustainable and resilient infrastructure, including regional and transborder infrastructure, to support economic development and human well-being, with a focus on affordable and equitable access for all

11 Sustainable Cities and Communities

2 By 2030, provide access to safe, affordable, accessible and sustainable transport systems for all, improving road safety, notably by expanding public transport, with special attention to the needs of those in vulnerable situations [...]

4 Strengthen efforts to protect and safeguard the world's cultural and natural heritage

5 By 2030, significantly reduce the number of deaths and the number of people affected and substantially decrease the direct economic losses relative to global gross domestic product caused by disasters, including water-related disasters [...]

6 By 2030, reduce the adverse per capita environmental impact of cities, including by paying special attention to air quality and municipal and other waste management

12 Responsible Consumption and Production 2 By 2030, achieve the sustainable management and efficient use of natural resources

4 By 2020, achieve the environmentally sound management of chemicals and all wastes throughout their life cycle, in accordance with agreed international frameworks, and significantly reduce their release to air, water and soil [...]

13 Climate Action

1 Strengthen resilience and adaptive capacity to climate-related hazards and natural disasters in all countries

14 Life Below Water

1

2025, prevent and significantly reduce marine pollution of all kinds, in particular from land-based activities, including marine debris and nutrient pollution

15 Life on Land strategies and accounts 
164

\subsection{Selection of sustainability indicators}

The conceptualization of SURSIST was undertaken with the relationship to the SDGs as main objective, in order to include the aspects highlighted by the United Nations for achieving sustainable development. Hence, a particular set of indicators was proposed to rate the degree of sustainability of urban surfaces. Table 2 describes the contribution of each of these indicators to sustainability, as well as the SDGs and targets addressed through their consideration (see Table 1).

Table 2. List of sustainability indicators to assess the contribution of urban surfaces to sustainability

\begin{tabular}{llll}
\hline ID & Indicator & Contribution to sustainability & SDGs (targets) \\
\hline$I_{1}$ & Albedo coefficient & Attenuation of Global Warming & $1(5), 13(1)$ \\
$I_{2}$ & Impact on water pollution & Improvement of water quality & $3(9), 6(3), 14(1)$ \\
$I_{3}$ & Threshold runoff & Flood mitigation & $1(5), 6(4), 11(5), 13(1)$ \\
$I_{4}$ & Energy from biomass & Energetic efficiency & $7(3), 8(4), 12(2)$ \\
$I_{5}$ & Carbon sequestration & Air purification & $3(9), 11(6), 12(4)$ \\
$I_{6}$ & Naturalness index & Safeguard of natural assets & $11(4)$ \\
$I_{7}$ & Injury crashes & Decrease in road traffic accidents & $3(6)$ \\
- & - & Enhancement of accessibility & $9(1), 11(2)$ \\
$I_{8}$ & Species number & Generation of ecosystems & $15(9)$ \\
$I_{9}$ & Agricultural land & Food production & $2(3)$ \\
$I_{10}$ & Noise level & Noise pollution abatement & $3(9)$ \\
\hline
\end{tabular}

The Albedo coefficient represents the fraction of solar energy reflected from the Earth back into space, providing a measure of the reflectivity of the Earth surface. This concept is extremely related to Global Warming, since this phenomenon is influenced by the rate of heat exchanges between the Earth surface and the atmosphere. Some authors like Bretz and Akbari (1997) and Taha (1997) have highlighted the efficiency of land cover to reduce surface and air temperatures near the ground. Therefore, the Albedo coefficient can have an important role in reducing the vulnerability of urban areas to climate-related hazards, as specified in SDGs 1 (5) and 13 (1).

Water purification is a key aspect in ensuring access to safe drinking water, which positively impacts on the health of the entire world. Providing reliable water services to the $27 \%$ of urban dwellers in the developing world who lack it is an essential long-term goal that will yield great health and economic benefits (UN-Water, 2010). If the land is not depleted by human activities and forestation is encouraged, water pollution might be reduced. Hence, communities engulfed with green environment are more likely to have clean water readily available without resorting to complex large scale treatment processes. For these reasons, the correlation of land cover to water quality parameters relates to the purification of water through SDGs 6 (3) and its subsequent positive impacts on the protection of living beings, represented by SDGs 3 (9) and 14 (1). 
Built and paved surfaces hinder the infiltration of water into the soil and contribute to runoff accumulation in urban areas. The increasing rate of built surfaces has resulted in dramatic changes in stormwater runoff, which consequently favours the occurrence of flooding phenomena in urban areas. Instead, vegetation coverage can trap runoff, acting as a watershed and facilitating the percolation of water into the soil mass. Up to four SDGs and targets, namely 1 (5), 6 (4), 11 (5) and 13 (1), focus on enhancing the resilience to natural disasters and improving the management of water resources.

The fourth indicator stands for the potential generation of energy from biomass derived from green and plant-related surfaces. Croplands, forestlands, and pasture and green areas provide an opportunity to intensify and increase the production of energy per unit land (Gallagher, 2006). Furthermore, the creation of energy from these surfaces is a natural phenomenon that does not require complex chains of processes. Consequently, this indicator is also aligned with the principles of sustainable development, due to its contribution to energy efficiency through SDGs 7 (3), 8 (4) 12 (2).

Carbon dioxide proportions in the atmosphere are one of the main responsible to both Climate Change and particle and ozone concentrations, such that finding methods to capture carbon contents emitted by human-related activities becomes essential. Land Use/Land Cover (LULC) change from natural to built-up areas is widely recognized as a net source of greenhouse gas emissions at the global scale. Deforestation, land clearing and other forms of LULC change driven by increasing population are main sources for carbon. Ross et al. (2016) pointed out that LULC classes and changes should be investigated to determine the carbon content of surfaces. SDGs 3 (9), 11 (6) and 12 (4) concern the eco-friendly management of releases to air.

The concept of naturalness is spatiotemporal, since the identification of characteristics making an item natural might vary according to the specifics of the situation (Lie, 2016). Still, naturalness cannot be neglected in the quest for achieving the SDGs, because landscape pattern as a tool for ecological sustainability must be pivoted on this concept. According to Renetzeder et al. (2010), a series of landscape metrics served to assess naturalness of Austrian and European landscapes as a proxy for their sustainability. Thus, this aspect contributes to safeguard the natural heritage through SDG 11 (4).

Mobility is a key factor for ensuring sustainable development, since it enables people to get access to products and services that are necessary for their daily lives. The integration of LULC policies has been recognized as an effective approach to guarantee a desired level of connectivity between urban areas (Cervero, 2003). However, the intensification in the development of urban surfaces has also been found to be positively correlated to the occurrence of crashes (Ivan et al., 2000), due to their high degree of vehicle admissibility. These dual considerations concern both SDG 3 (6), which seeks to reduce the number of injuries from vehicle accidents, and SDGs 9 (1) and 11 (2), intended to improve accessibility for all. 
Biodiversity offsets seek to balance the needs of development and nature conservation, such that the loss of biodiversity caused by development can be compensated by an equivalent increase at a different geographic locality. If the gains from the offset equal the losses of development, there is no net loss of biodiversity (Buschke, 2017). A better understanding of the connections between biodiversity and the abiotic environment along changing land use is crucial in developing sustainable measures to conserve biodiversity under global change (Tukiainen et al., 2017). The generation of ecosystems and its impact on the integration of biodiversity on planning was related to SDG 15 (9).

The agricultural productivity of land is essential for the socioeconomic development and wellbeing of humans (Olesen and Bindi, 2002). The trends in LULC change worldwide are characterized by both the increase in built-up surfaces and the reduction of arable land. This decrease in cultivated land not only limits land productivity, but also affects food security (Zhang et al., 2014). The results presented by Jin et al. (2015) indicated that the conversion of cultivated land into built-up surfaces greatly impacted on the level and spatial pattern of agricultural productivity. These aspects help meeting SDG 2 (3), since the presence of agricultural land increases the rate of food productivity.

Estimating and controlling urban noise pollution have been identified as major challenges for the environmental planning and management of cities (Xie et al., 2011). The LULC alterations derived from the intensification of urban development can produce a series of environmental impacts, including noise pollution (King et al., 2012). Nuisances like annoyance, sleep disturbance and other health effects caused by noise exposure might be influenced by the degree of development of the surrounding urban surfaces. Consequently, these considerations can be associated with SDG 3 (9), which addresses illnesses from air pollution.

\subsection{Characterization of indicators}

The characterization of the indicators listed in Table 2 was carried out considering the types of urban surfaces to be assessed using SURSIST. This was accomplished with the support of the CORINE Land Cover (CLC) program as a geographical framework. The CLC project is a scale 1:100,000 land cover database for the European Union, driven by the European Environment Agency (EEA), which analyses information collected through remote sensing (Stathopoulou and Cartalis, 2007). Table 3 shows the 3-level hierarchical classification provided by the CLC project.

Hence, one of the cornerstones in the design of SURSIST consisted of crossing the data included in Table 2 with those shown in Table 3, in order to determine the response presented by each land cover type in terms of the proposed list of sustainability indicators. In the end, this task enabled finding out which urban surfaces contributed the most to the degree of sustainability of cities, facilitating the identification of opportunities to increase it through the replacement of some covers by others. 
Table 3. CORINE Land Cover (CLC) nomenclature (EEA, 1997)

\begin{tabular}{|c|c|c|}
\hline Level 1 & Level 2 & Level 3 \\
\hline \multirow{11}{*}{$\begin{array}{l}1 \text { Artificial } \\
\text { surfaces }\end{array}$} & \multirow[t]{2}{*}{11 Urban fabric } & 111 Continuous urban fabric \\
\hline & & 112 Discontinuous urban fabric \\
\hline & \multirow{4}{*}{$\begin{array}{l}12 \text { Industrial, commercial } \\
\text { and transport units }\end{array}$} & 121 Industrial or commercial units \\
\hline & & 122 Road and rail networks and associated land \\
\hline & & 123 Port areas \\
\hline & & 124 Airports \\
\hline & \multirow{3}{*}{$\begin{array}{l}13 \text { Mine, dump and } \\
\text { construction sites }\end{array}$} & 131 Mineral extraction sites \\
\hline & & 132 Dump sites \\
\hline & & 133 Construction sites \\
\hline & \multirow{2}{*}{$\begin{array}{l}14 \text { Artificial, non- } \\
\text { agricultural vegetated areas }\end{array}$} & 141 Green urban areas \\
\hline & & 142 Sport and leisure facilities \\
\hline \multirow{11}{*}{$\begin{array}{l}2 \text { Agricultural } \\
\text { areas }\end{array}$} & \multirow[t]{3}{*}{21 Arable land } & 211 Non-irrigated arable land \\
\hline & & 212 Permanently irrigated land \\
\hline & & 213 Rice fields \\
\hline & \multirow{3}{*}{22 Permanent crops } & 221 Vineyards \\
\hline & & 222 Fruit trees and berry plantations \\
\hline & & 223 Olive groves \\
\hline & 23 Pastures & 231 Pastures \\
\hline & \multirow{4}{*}{$\begin{array}{l}24 \text { Heterogeneous } \\
\text { agricultural areas }\end{array}$} & 241 Annual crops associated with permanent crops \\
\hline & & 242 Complex cultivation patterns \\
\hline & & $\begin{array}{l}243 \text { Land principally occupied by agriculture, with } \\
\text { significant areas of natural vegetation }\end{array}$ \\
\hline & & 244 Agro-forestry areas \\
\hline \multirow{10}{*}{$\begin{array}{l}3 \text { Forest and } \\
\text { semi natural } \\
\text { areas }\end{array}$} & 31 Forests & 311 Broad-leaved forest \\
\hline & \multirow{4}{*}{$\begin{array}{l}32 \text { Scrub and/or herbaceous } \\
\text { vegetation associations }\end{array}$} & 321 Natural grasslands \\
\hline & & 322 Moors and heathland \\
\hline & & 323 Sclerophyllous vegetation \\
\hline & & 324 Transitional woodland-shrub \\
\hline & \multirow{5}{*}{$\begin{array}{l}33 \text { Open spaces with little } \\
\text { or no vegetation }\end{array}$} & 331 Beaches, dunes, sands \\
\hline & & 332 Bare rocks \\
\hline & & 333 Sparsely vegetated areas \\
\hline & & 334 Burnt areas \\
\hline & & 335 Glaciers and perpetual snow \\
\hline \multirow{5}{*}{4 Wetlands } & \multirow[t]{2}{*}{41 Inland wetlands } & 411 Inland marshes \\
\hline & & 412 Peat bogs \\
\hline & \multirow[t]{3}{*}{42 Maritime wetlands } & 421 Salt marshes \\
\hline & & 422 Salines \\
\hline & & 423 Intertidal flats \\
\hline \multirow[t]{5}{*}{5 Water bodies } & \multirow[t]{2}{*}{51 Inland waters } & 511 Water courses \\
\hline & & 512 Water bodies \\
\hline & \multirow[t]{3}{*}{52 Marine waters } & 521 Coastal lagoons \\
\hline & & 522 Estuaries \\
\hline & & 523 Sea and ocean \\
\hline
\end{tabular}


281

287

288

\subsection{Weighting of indicators}

The weights of the indicators listed in Table 2 were determined according to the number of SDGs and targets to which they were related. Instead of undertaking this process through direct allocation, the relative importance of the indicators was calculated using the Analytic Hierarchy Process (AHP). This course of action was adopted to give more importance to those indicators proving to be capable of addressing a higher number of the concerns posed by the SDGs. The fact that the United Nations lack a weighting system to prioritize some targets over others, as demonstrated through its SDG Index (Sachs et al., 2017), guaranteed the convenience of the proposed approach.

The AHP method, created by Saaty (1990), is based on quantifying a list of linguistic comparisons through a pairwise numerical scale. In this case, these qualitative comparisons were derived from the degree of contribution of the indicators to achieve the SDGs. Table 4 represents the adapted scale proposed, which compares two indicators $I_{i}$ and $I_{j}$ according to the number $N$ of targets in the SDGs they address.

Table 4. Adapted pairwise comparison scale for weighting the sustainability indicators

\begin{tabular}{lllr}
\hline $\boldsymbol{I}_{\boldsymbol{i}}$ & $\boldsymbol{I}_{\boldsymbol{j}}$ & Importance $\left(\boldsymbol{I}_{\boldsymbol{i}}\right.$ with respect to $\left.\boldsymbol{I}_{\boldsymbol{j}}\right)$ & Numerical value \\
\hline$N$ & $N+3$ & Much less important & $1 / 7$ \\
$N$ & $N+2$ & Less important & $1 / 5$ \\
$N$ & $N+1$ & Slightly less important & $1 / 3$ \\
$N$ & $N$ & Equally important & 1 \\
$N+1$ & $N$ & Slightly more important & 3 \\
$N+2$ & $N$ & More important & 5 \\
$N+3$ & $N$ & Much more important & 7 \\
\hline
\end{tabular}

The $p$ comparisons made according to this scale are arranged in the form of a matrix, such that the consistency of the pairwise comparison is measured through the maximum eigenvalue of the matrix $\left(\lambda_{\max }\right)$. Hence, the matrix is completely consistent when $\lambda_{\max }=$ $p$, whilst it becomes increasingly inconsistent as the eigenvalue grows according to Eq. (1):

$$
\text { C.R. }=\frac{C . I .}{R . I .}=\frac{\frac{\lambda_{\max }-p}{p-1}}{R . I .}<0.1
$$

where $C . R$. is the consistency ratio, $C . I$. is the consistency index and $R . I$. is the random consistency index, which represents an average $C$. $I$. for a large number of randomly generated matrices of the same order. 
308

309

310

311

312

313

314

\subsection{Composite sustainability index}

This step aimed at producing a composite index indicating the degree of contribution of the urban surfaces of an entire city to achieving the SDGs. This index was built from the aggregation of the ratings of indicators across the land cover types shown in Table 3. This aggregation process was carried out with the support of the Technique for Order of Preference by Similarity to Ideal Solution (TOPSIS) as a theoretical framework.

The TOPSIS method was conceived by Hwang and Yoon (1981) to find the alternative providing the best solution to problems characterized by having multiple criteria. According to the working principles of TOPSIS, this preferred alternative does not only keep the shortest distance from a positive ideal solution $\left(A^{+}\right)$, but also the longest distance from a negative ideal solution $\left(A^{-}\right)$. The application of the TOPSIS method is sequential and consists of the following steps:

1. Establish a rating matrix indicating the ratings $r_{i j}$ of a set of different alternatives $A_{i}\langle i=1,2, \ldots, m\rangle$ across the indicators $I_{j}\langle j=1,2, \ldots, n\rangle$.

\begin{tabular}{c|cccc} 
& $\boldsymbol{I}_{\mathbf{1}}$ & $\boldsymbol{I}_{\mathbf{2}}$ & $\ldots$ & $\boldsymbol{I}_{\boldsymbol{n}}$ \\
\hline $\boldsymbol{A}_{\mathbf{1}}$ & $r_{11}$ & $r_{12}$ & $\ldots$ & $r_{1 n}$ \\
$\boldsymbol{A}_{\mathbf{2}}$ & $r_{21}$ & $r_{22}$ & $\ldots$ & $r_{2 n}$ \\
$\ldots$ & $\ldots$ & $\ldots$ & $\ldots$ & $\ldots$ \\
$\boldsymbol{A}_{\boldsymbol{m}}$ & $r_{m 1}$ & $r_{m 2}$ & $\ldots$ & $r_{m n}$
\end{tabular}

2. Normalize the rating matrix according to the following expressions, which determine the normalized rating $n_{i j}$ for the alternative $A_{i}$ with respect to the indicator $I_{j}$ :

$n_{i j}=\frac{r_{i j}}{\max _{i} z_{j}^{\prime}}, \quad$ if $I_{j}$ is a benefit indicator

$n_{i j}=\frac{\min _{i} z_{j}}{r_{i j}}, \quad$ if $I_{j}$ is a cost indicator

The application of Eqs. (3) and (4) prevent rank reversal and enable obtaining the best alternative to the problem in "absolute" terms (García-Cascales and Lamata, 2012), since they account for the maximum and minimum achievable ratings $\left(\max _{i} z_{j}\right.$ and $\min _{i} z_{j}$ ) in the space of alternatives. In those cases in which an indicator includes negative ratings, they were transformed into positive values using the formula proposed by Ginevicius and Podvezko (2007): 


$$
\overline{r_{l j}}=r_{i j}+\left|\min _{i} r_{i j}\right|+1
$$

3. Build the weighted normalized rating matrix as follows:

$$
v_{i j}=w_{j} \times n_{i j}
$$

where $v_{i j}$ is the weighted normalized rating for the alternative $A_{i}$ with respect to the indicator $I_{j}$ and $w_{j}$ is the weight of the $I_{j}$, such that $\sum_{j=1}^{n} w_{j}=1$.

4. Calculate the positive ideal solution $\left(A^{+}\right)$and negative ideal solution $\left(A^{-}\right)$:

$$
A^{+}=w_{j}
$$

$$
A^{-}=w_{j} * \frac{n_{i j}\left(\min _{i} z_{j}\right)}{n_{i j}\left(\max _{i} z_{j}\right)}
$$

where $n_{i j}\left(\min _{i} z_{j}\right)$ and $n_{i j}\left(\max _{i} z_{j}\right)$ correspond to the normalized ratings of $\max _{i} z_{j}$ and $\min _{i} z_{j}$.

5. Determine the Euclidean positive and negative distance $\left(d_{i}^{+}\right.$and $\left.d_{i}^{-}\right)$from each alternative to $A^{+}$and $A^{-}$:

$$
d_{i}^{+}=\sqrt{\sum_{j=1}^{n}\left(v_{i j}-v_{j}^{+}\right)^{2}}
$$

$$
d_{i}^{-}=\sqrt{\sum_{j=1}^{n}\left(v_{i j}-v_{j}^{-}\right)^{2}}
$$

where $v_{j}^{+}$and $v_{j}^{-}$are the positive and negative ideal weighted normalized rating for the indicator $j$, respectively.

6. Compute the relative closeness $R C_{i}$ from the alternative to the ideal solution:

$$
R C_{i}=\frac{d_{i}^{-}}{d_{i}^{+}+d_{i}^{-}}
$$


such that $0 \leq R C_{i} \leq 1$, since $d_{i}^{+} \geq 0$ and $d_{i}^{+} \geq 0$.

350 3. Results and discussion: case studies of Santander and Valen351 cia, Spain

The results of this research stemmed from the application of the Sustainable Urban Surface Rating System (SURSIST) to two case studies focused on the cities of Santander and Valencia, located in the north and east coasts of Spain (see Fig. 2). Santander and Valencia had 172,656 and 790,201 inhabitants and covered 34.76 and $134.65 \mathrm{~km}^{2}$ by 2016, respectively. Both cities orient their economic activity to the tertiary sector, with about $70 \%$ and $84 \%$ of the population working on service-related activities (INE, 2016).

A notable difference between these two cities lies in their weather. Santander is characterized by an Oceanic climate consisting of temperate summers and cool winters, with a not very broad range of temperatures and moist conditions all year round. In contrast,

362 Valencia has a dry Mediterranean climate that is translated into warm summers and tem363 perate winters, experiencing high temperatures in August and intense rainfall events in 364 autumn. As a result, Santander and Valencia belong to the types Cfb and Bsh in the Köppen classification, respectively (Chazarra et al., 2011).

366 Hence, the aim of this section was to measure the sustainability of both cities in terms 367 of their urban surfaces. This analysis undertaken throughout a time horizon of 16 years 368 (from 1990 to 2006), in order to get insight into the evolution of the sustainability of the 369 urban skin of Santander and Valencia over the years. Their demographic and climatic 370 differences further increased the interest in the results obtained, since they enabled testing 371 the implementation of SURSIST through rather dissimilar cases. 


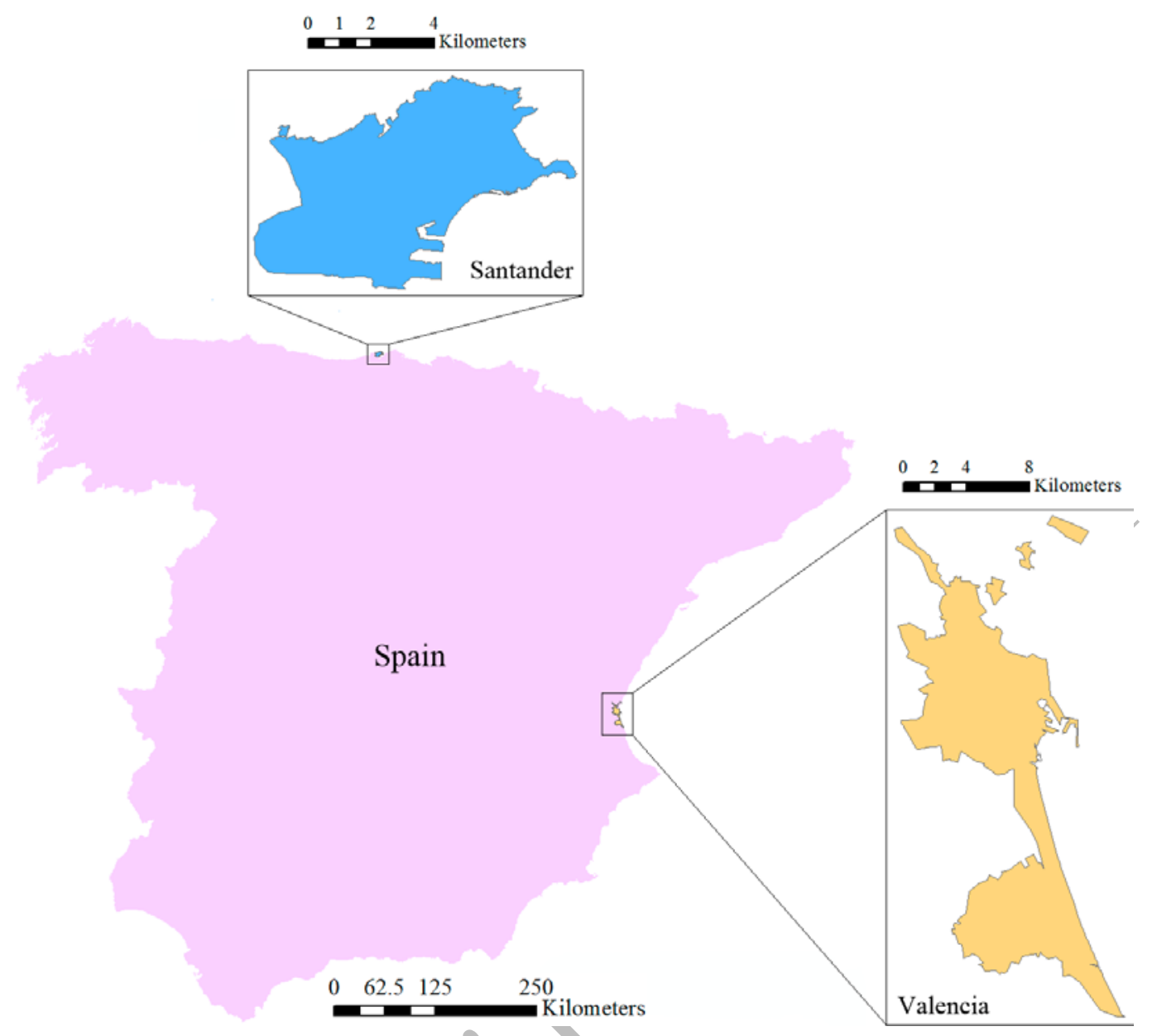

Fig. 2. Location of Santander and Valencia in relation to Spain 381 3. Fig. 3 illustrates these maps, which provide evidence of the increasing degree of de382 velopment experienced by both cities over the years. This evolution stemmed from the 383 growth in the area covered by built-up surfaces, especially through the categories 111 and 384112 (continuous and discontinuous urban fabric). 


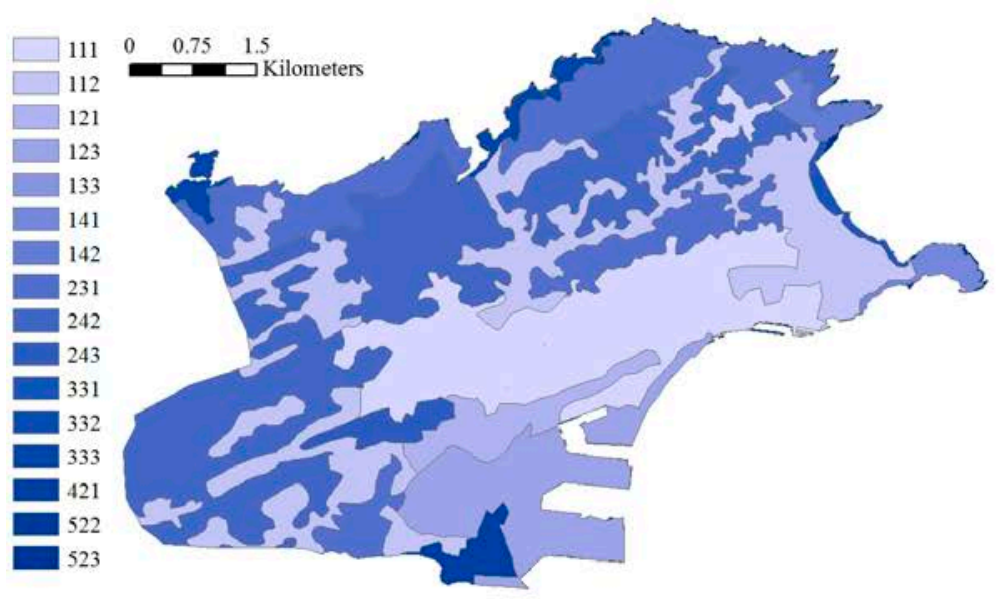

a)

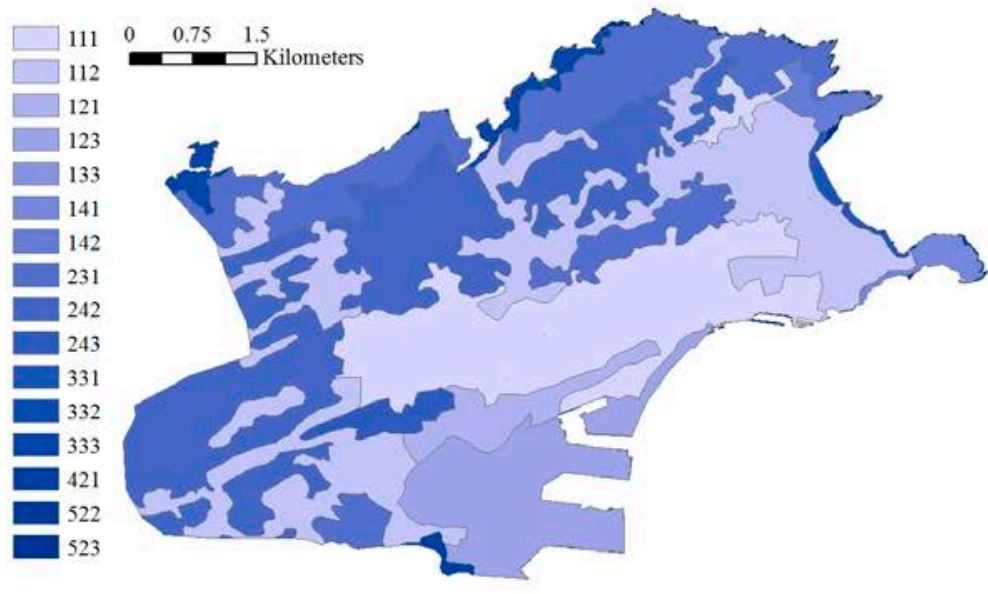

c)

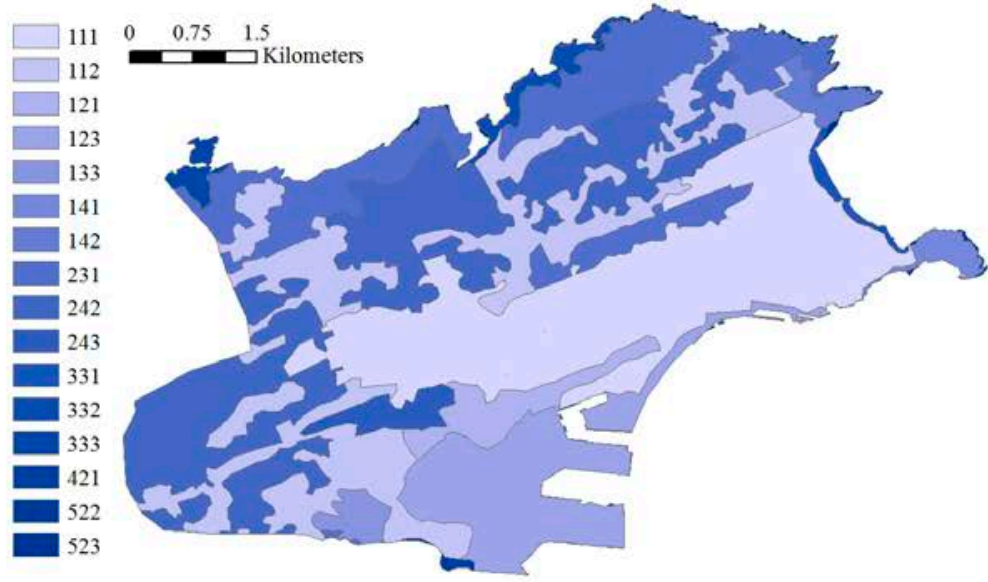

e)

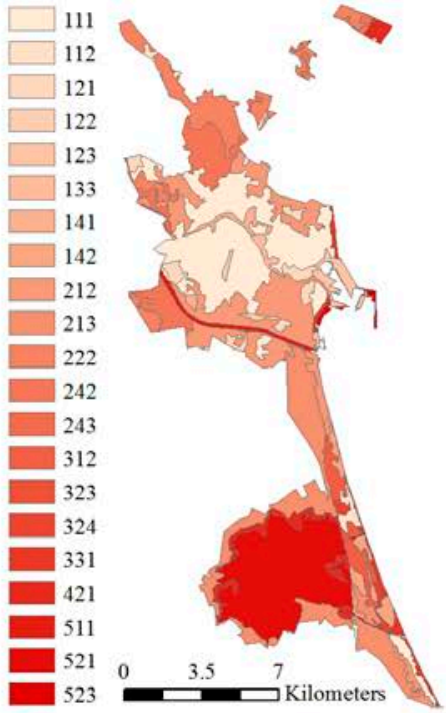

b)

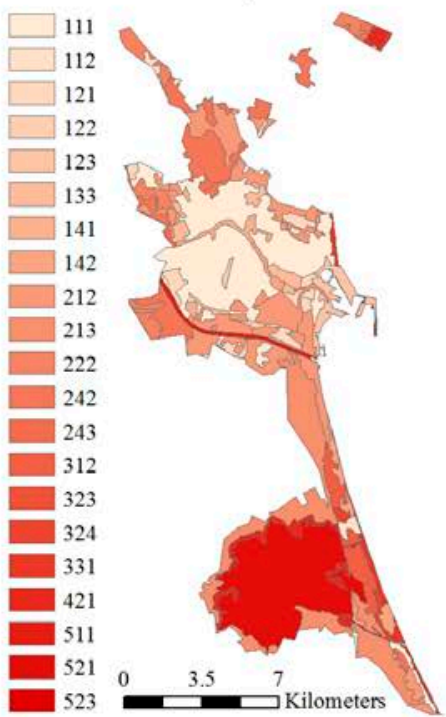

d)

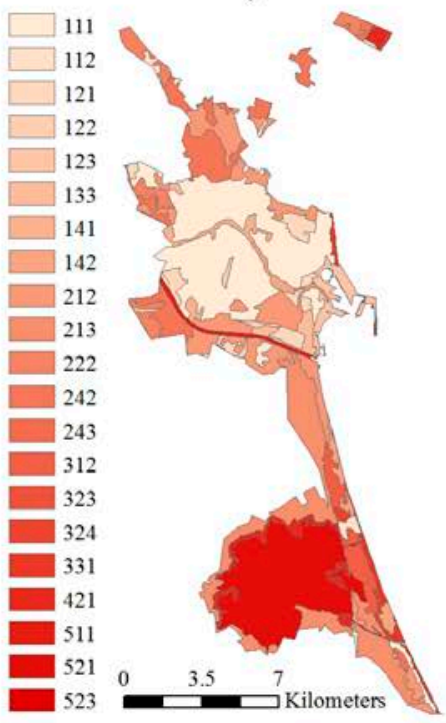

f)

Fig. 3. Land cover maps derived from the CORINE Land Cover (CLC) project (level 3) a) Santander 1990 b) Valencia 1990 c) Santander 2000 d) Valencia 2000 e) Santander 2006 f) Valencia 2006 
Although the CLC project is also available in Spain for 2012, the time horizon of the study was limited to 2006, because the 2012 map was prepared from the changes observed in the Spanish Land Use and Land Cover Information System (SIOSE) between 2005 and 2011. Consequently, the variation in the process of production for the CLC map corresponding to 2012 invalidated its use for comparative purposes. Furthermore, the SIOSE project is a finer alternative to the CLC project (scale 1/25,000) (SIOSE, 2012), whose increased level of detail hindered the collection of information to characterize the indicators in Table 2.

Table 5 shows the ratings of each urban surface present in Santander and/or Valencia across the indicators listed in Table 2 according to the codification of the CLC project (see Table 3). $I_{1}$ corresponded to the values of the Albedo coefficient for urban surfaces found in different sources (Coakley, 2003; Dobos, 2005; Wei et al., 2001). The determination of $I_{2}$ was undertaken from the correlation coefficients between land cover and water quality presented by Wang et al. (2014). Such coefficients, which originally ranged from -1 to 1 , were normalized to remain between 0 and 1 . The values of threshold runoff (mm) needed for rating $I_{3}$ were approved by law through the Spanish Official State Gazette (BOE, 2016). $I_{4}$ was evaluated using the report prepared by the Intergovernmental Panel on Climate Change (IPCC), which provided an estimate of the global potential energy from biomass (EJ) associated with different land covers (IPCC, 2000). The potential for carbon sequestration ( $\mathrm{Gg} \mathrm{CO}_{2}$ eq./year) expressed by $I_{5}$ was rated based on the report emitted by the Basque Government (Artetxe Arrien et al., 2014), which calculated this attribute for six groups: forests, crops, pastures, wetlands, settlements and others. $I_{6}$ was quantified using a range of 0 to 1 from several studies (Machado, 2004; Rojas et al., 2013; Sepúlveda-Zúñiga et al., 2012) intended to produce a naturalness index for different land cover categories, depending on the degree of disturbance produced by humans. $I_{7}$ contributed twice to the SDGs, since this factor was an indicator of both traffic accidents and accessibility (see Table 2). Hence, this indicator was represented by the number of crashes per ha reported by Kim and Yamashita (2002). Biodiversity was measured through $I_{8}$, which represented the mean standardized species number per $\mathrm{m}^{2}$ for specific land cover types, including vascular plants, moss and mollusks (Koellner and Scholz, 2008). The opportunity for food production of urban surfaces was valuated as a binary indicator $\left(I_{9}\right)$ according to the Food and Agriculture Organization of the United Nations (FAOSTAT), which defines agricultural land as that devoted to crops, pastures, mowing, meadows or vegetable garden (Lutzenberger et al., 2014). Finally, $I_{10}$ provided an indicator of the noise level (dBA) associated with different land covers. Its characterization was based on the consideration of noise source areas and transmission loss areas, as well as the noise environments they both produced (Caswell and Jakus, 1977). 
Table 5. Ratings for the CORINE Land Cover (CLC) codes (level 3) included in Santander and/or Valencia across the sustainability indicators

\begin{tabular}{lrrrrrrrrrrrr}
\hline CLC & $\boldsymbol{I}_{\mathbf{1}}$ & $\boldsymbol{I}_{\mathbf{2}}$ & \multicolumn{1}{c}{$\boldsymbol{I}_{\mathbf{3}}$} & $\boldsymbol{I}_{\mathbf{4}}$ & $\boldsymbol{I}_{\mathbf{5}}$ & \multicolumn{1}{c}{$\boldsymbol{I}_{\mathbf{6}}$} & $\boldsymbol{I}_{\mathbf{7}}$ & \multicolumn{2}{c}{$\boldsymbol{I}_{\mathbf{8}}$} & \multicolumn{2}{c}{$\boldsymbol{I}_{\mathbf{9}}$} & \multicolumn{2}{c}{$\boldsymbol{I}_{\mathbf{1 0}}$} \\
\hline 111 & 0.10 & 0.0 & 1 & 0 & -74 & 0.00 & 0.200 & 12.7 & 0.0 & 76 \\
112 & 0.12 & 0.0 & 14 & 0 & -74 & 0.00 & 0.175 & 18.0 & 0.0 & 55 \\
121 & 0.15 & 0.0 & 4 & 0 & -74 & 0.00 & 0.161 & 20.6 & 0.0 & 75 \\
122 & 0.08 & 0.0 & 1 & 0 & -74 & 0.00 & 0.208 & 28.6 & 0.0 & 79 \\
123 & 0.15 & 0.0 & 1 & 0 & -74 & 0.00 & 0.119 & 17.8 & 0.0 & 60 \\
133 & 0.15 & 0.0 & 14 & 0 & -74 & 0.00 & 0.119 & 15.5 & 0.0 & 40 \\
141 & 0.21 & 0.3 & 23 & 525 & 193 & 0.25 & 0.044 & 24.6 & 1.0 & 40 \\
142 & 0.15 & 0.0 & 32 & 0 & -74 & 0.00 & 0.044 & 17.8 & 0.0 & 60 \\
212 & 0.18 & 0.1 & 23 & 672 & 49 & 0.25 & 0.005 & 12.6 & 1.0 & 35 \\
213 & 0.18 & 0.1 & 25 & 672 & 49 & 0.25 & 0.005 & 4.9 & 1.0 & 35 \\
222 & 0.18 & 0.1 & 31 & 672 & 49 & 0.25 & 0.005 & 21.7 & 1.0 & 35 \\
231 & 0.19 & 0.3 & 44 & 672 & 193 & 0.50 & 0.005 & 27.9 & 1.0 & 35 \\
241 & 0.18 & 0.1 & 41 & 672 & 49 & 0.25 & 0.005 & 20.6 & 1.0 & 35 \\
242 & 0.18 & 0.1 & 39 & 672 & 49 & 0.25 & 0.005 & 20.6 & 1.0 & 35 \\
243 & 0.19 & 0.3 & 24 & 672 & 49 & 0.25 & 0.005 & 34.3 & 1.0 & 35 \\
312 & 0.16 & 1.0 & 47 & 437 & 2,869 & 1.00 & 0.000 & 22.9 & 0.0 & 35 \\
321 & 0.19 & 0.3 & 29 & 525 & 193 & 0.50 & 0.005 & 30.8 & 1.0 & 35 \\
322 & 0.17 & 0.3 & 31 & 525 & 193 & 0.75 & 0.000 & 28.7 & 0.0 & 35 \\
323 & 0.17 & 0.3 & 29 & 525 & 193 & 0.75 & 0.000 & 30.5 & 0.0 & 35 \\
324 & 0.17 & 0.3 & 34 & 525 & 193 & 0.75 & 0.000 & 32.2 & 0.0 & 35 \\
331 & 0.30 & 0.3 & 152 & 0 & -1 & 0.50 & 0.000 & 9.1 & 0.0 & 35 \\
332 & 0.17 & 0.3 & 2 & 0 & -1 & 0.25 & 0.000 & 17.5 & 0.0 & 35 \\
333 & 0.17 & 0.3 & 20 & 0 & -1 & 0.25 & 0.002 & 33.6 & 0.0 & 35 \\
421 & 0.10 & 0.5 & 2 & 0 & 0 & 0.75 & 0.000 & 31.5 & 0.0 & 35 \\
511 & 0.10 & 0.5 & 0 & 0 & 0 & 0.50 & 0.000 & 14.1 & 0.0 & 35 \\
512 & 0.10 & 0.5 & 0 & 0 & 0 & 0.50 & 0.000 & 14.1 & 0.0 & 35 \\
521 & 0.10 & 0.5 & 0 & 0 & 0 & 0.50 & 0.000 & 14.1 & 0.0 & 35 \\
522 & 0.10 & 0.5 & 0 & 0 & 0 & 0.50 & 0.000 & 14.1 & 0.0 & 35 \\
523 & 0.07 & 0.5 & 0 & 0 & 0 & 0.50 & 0.000 & 14.1 & 0.0 & 35 \\
\hline Units & {$[0,11$} & Score & mm & EJ & Gg CO & eq./yr. & Score & Crashes/ha & Std. species/m² & Binary & dBA \\
\hline & & & & & & & & & &
\end{tabular}

\subsection{Weighting of indicators}

The next step in the application of SURSIST concerned the calculation of the weights of the sustainability indicators proposed in Table 1. In other words, this enabled deter-

433 mining their relative importance in the evaluation of the contribution of the urban surfaces 434 forming the skin of Santander and Valencia to achieve the SDGs. This task was carried 435 out through the implementation of the Analytic Hierarchy Process (AHP).

436 Prior to the calculation of weights, $I_{7}$ was partitioned into two sub-indicators $\left(I_{7 a}\right.$ and $437 I_{7 b}$ ) to represent its duality, since this indicator contribute to the SDGs through two con438 flicting factors, such as decrease in road traffic accidents (cost sub-indicator) and en439 hancement of accessibility (benefit sub-indicator) (see Table 1). Then, the indicators were 
440

441

442

443

444

445

446

447

448

449

450

451

452

453

454

455

456

457

458

459

460

461

462

463

464

465

466

467

468

469

470

471

472

473

474

475

476

compared to each other based on the number of targets in the SDGs to which they were related, as schematized in Table 4. For instance, the first two indicators were related to 2 $\left(I_{1}\right)$ and $3\left(I_{2}\right)$ targets, respectively, such that $N=2$ in this case (see Table 2). Therefore, $I_{1}(N)$ was slightly less important than $I_{2}(N+1)$, which corresponded to a numerical value of $1 / 3$, according to Table 4 . The application of this process to the remaining combinations of pairs of indicators ( $I_{i}$ with respect to $I_{j}$ ) yielded the values forming the comparison matrix, which were used to determine the weights listed in Table 6 through the AHP method.

Table 6. Weights obtained for the proposed sustainability indicators according to the number of targets in the Sustainable Development Goals (SDGs) they addressed

\begin{tabular}{lrrrrrrrrrrrrr}
\hline Indicator & $I_{1}$ & $I_{2}$ & $I_{3}$ & $I_{4}$ & $I_{5}$ & $I_{6}$ & $I_{7 a}$ & $I_{7 b}$ & $I_{8}$ & \multicolumn{1}{c}{$I_{9}$} & $I_{10}$ \\
\hline SDGs (targets) & 2 & 3 & 4 & 3 & 3 & 1 & 1 & 2 & 1 & 1 & 1 \\
\hline Weight & 0.071 & 0.146 & 0.277 & 0.146 & 0.146 & 0.029 & 0.029 & 0.071 & 0.029 & 0.029 & 0.029 \\
\hline
\end{tabular}

The consistency of these weights was ensured by the value of $C$. $R$. obtained (0.015) for the comparison matrix using Eq. (1). These results highlighted the importance granted by the United Nations to the management of a critically scarce resource like water and the mitigation of water-related disasters favored by Climate Change $\left(I_{3}\right)$. The second level of importance corresponded to protecting natural resources, either directly by controlling the pollution that affects both air $\left(I_{5}\right)$ and water $\left(I_{2}\right)$ or indirectly through the search for potential sources to improve the energetic efficiency $\left(I_{4}\right)$ of urban areas. Attenuating urban warming $\left(I_{1}\right)$ and guaranteeing an adequate degree of accessibility $\left(I_{7 b}\right)$ were the next factors in reaching higher weights. The remaining aspects under consideration $\left(I_{6}, I_{7 a}, I_{8}\right.$, $I_{9}$ and $I_{10}$ ) only related to one SDG each and, therefore, received the lowest degree of importance.

\subsection{Composite sustainability index}

The characterization and weighting of indicators provided all the inputs required to apply the Technique for Order of Preference by Similarity to Ideal Solution (TOPSIS). Hence, the TOPSIS method was used to calculate the composite sustainability indices for Santander and Valencia in the time horizon from 1990 to 2006. The first task required to implement the TOPSIS method consisted of building the rating matrix as indicated in Eq. (2). The multiplication of the ratings obtained in Table 5 by the weighted sum of the areas covered by each type of land cover in Santander and Valencia, as illustrated in Fig. 3, yielded the rating matrix shown in Table 7 . Based on the ratings achieved by both cities in 1990, 2000 and 2006 and those corresponding to single land cover types (see Table 5), the values of $\max _{i} z_{j}$ and $\min _{i} z_{j}$ included in Table 7 were suggested to establish extreme ratings that might be reached in rather sustainable and unsustainable environments. 
479

480

481

482

483

484

485

486

487

488

489

490

491

492

Table 7. Rating matrix and maximum and minimum achievable ratings for the proposed sustainability indicators

\begin{tabular}{|c|c|c|c|c|c|c|c|c|}
\hline \multirow{2}{*}{ Indicator } & \multicolumn{3}{|c|}{ Santander } & \multicolumn{3}{|l|}{ Valencia } & \multirow{2}{*}{$\max _{i} z_{j}$} & \multirow{2}{*}{$\min _{i} z_{j}$} \\
\hline & 1990 & 2000 & 2006 & 1990 & 2000 & 2006 & & \\
\hline$I_{1}$ & 0.150 & 0.148 & 0.146 & 0.145 & 0.143 & 0.141 & 0.19 & 0.10 \\
\hline$I_{2}$ & 0.098 & 0.087 & 0.082 & 0.189 & 0.189 & 0.186 & 1.0 & 0.0 \\
\hline$I_{3}$ & 22.615 & 21.57 & 19.874 & 17.382 & 16.926 & 16.134 & 29 & 9 \\
\hline$I_{4}$ & 297.367 & 272.805 & 258.189 & 316.231 & 295.077 & 273.449 & 400 & 150 \\
\hline$I_{5}$ & 8.227 & 1.297 & -3.023 & 78.132 & 84.875 & 81.541 & 150 & -25 \\
\hline$I_{6}$ & 0.172 & 0.152 & 0.142 & 0.267 & 0.261 & 0.253 & 0.60 & 0.00 \\
\hline$I_{7}$ & 0.09 & 0.098 & 0.103 & 0.054 & 0.058 & 0.065 & 0.150 & 0.030 \\
\hline$I_{8}$ & 20.028 & 19.676 & 19.001 & 14.654 & 14.552 & 14.539 & & 10.0 \\
\hline$I_{9}$ & 0.445 & 0.408 & 0.386 & 0.451 & 0.417 & 0.386 & & 0.0 \\
\hline$I_{10}$ & 50.099 & 51.203 & 52.913 & 45.771 & 46.472 & 47.96 & & 35 \\
\hline
\end{tabular}

To provide a visual representation of the values reached by both Santander and Valencia across each indicator, Fig. 4 depicts their normalized ratings according to the maximum and minimum feasible ratings shown in Table 7. The overall trend in both cases pointed out to a clear decrease in the scores achieved per indicator over the years. The only exception to this trend was $I_{7}$, due to the improved accessibility provided by the progressive increase in built-up surfaces observed in Fig. 3.

The greatest differences between both cities were found in the presence of forests and semi natural areas, which was much higher in Valencia and resulted in positive impacts on the indicators related to air and water quality and naturalness $\left(I_{2}, I_{5}\right.$ and $\left.I_{6}\right)$. In contrast, Santander proved to have a better ratio of permeable zones and surfaces favoring mobility to the overall area of the city $\left(I_{3}\right.$ and $\left.I_{7}\right)$, as well as a more adequate land configuration in terms of presence of species $\left(I_{8}\right)$. 


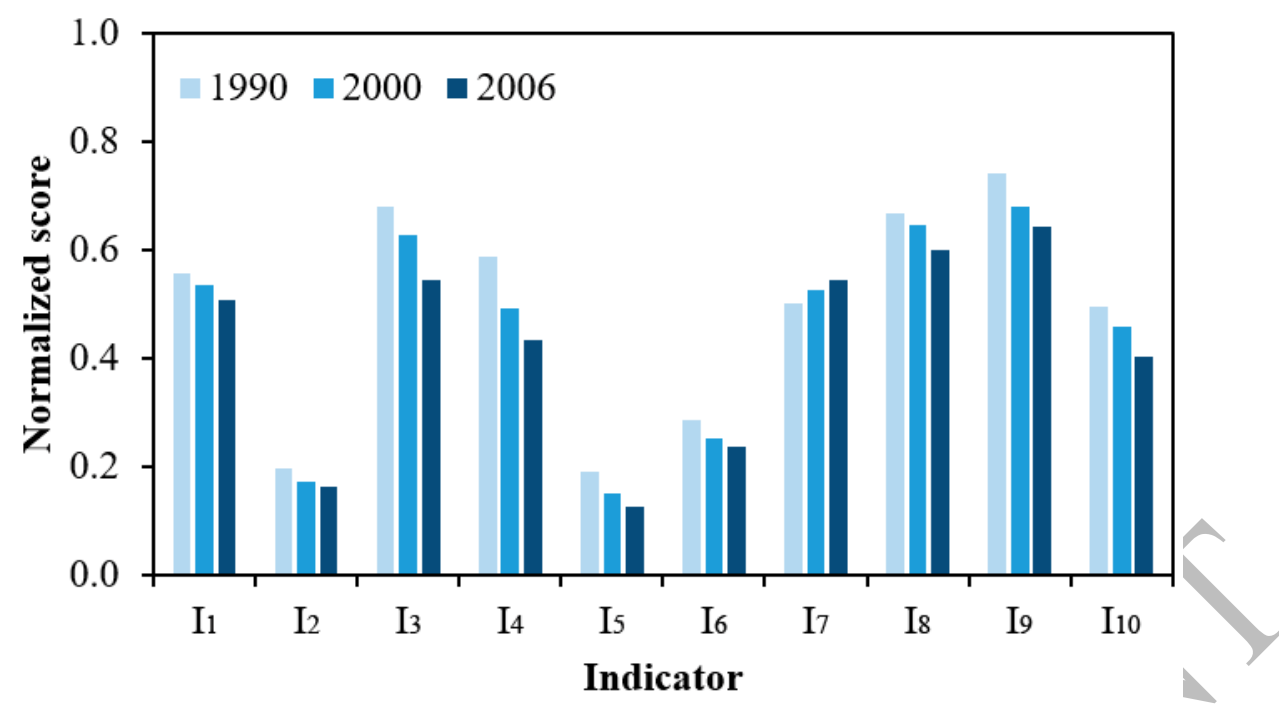

a)

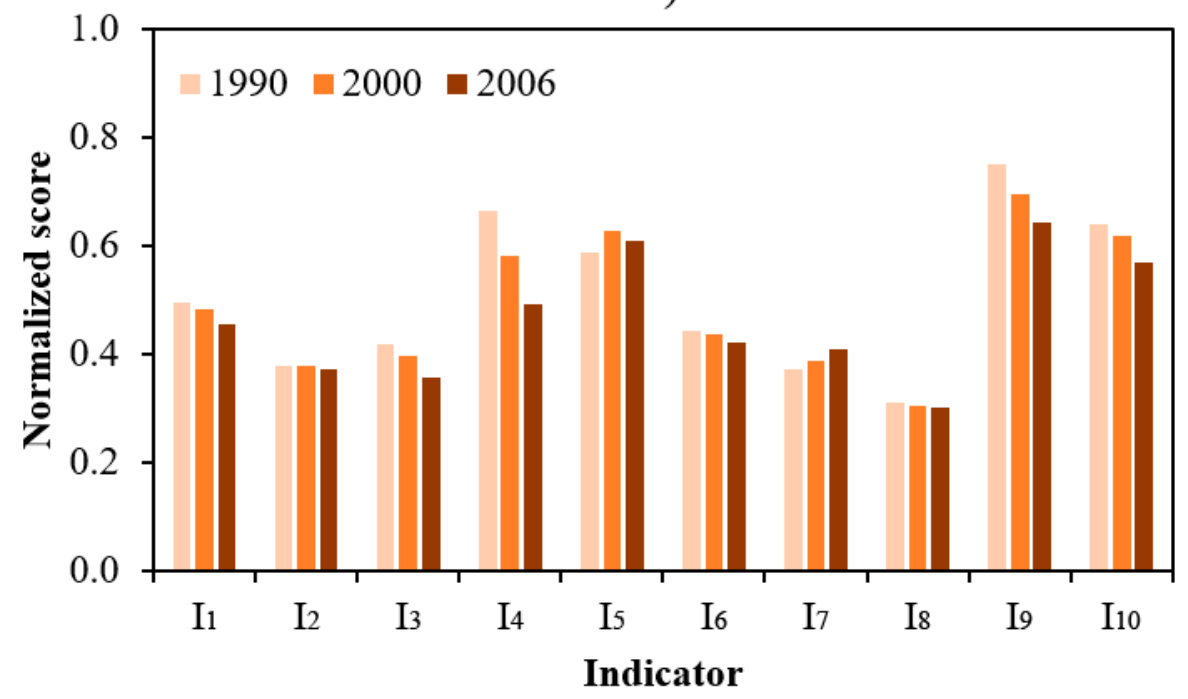

b)

494

495

496

497

498

499

500

501

502

503

504

505

506

507

Fig. 4. Normalized scores for the sustainability indicators in a) Santander b) Valencia in 1990, 2000 and 2006

Once the original ratings in Table 7 were normalized and transformed when necessary through Eqs. (3), (4) and (5), the weighted normalized matrix was built using Eq. (6) to incorporate the degree of importance allocated to each indicator (see Table 6) into the process. Then, the calculation of the Euclidean distances $d_{i}^{+}$and $d_{i}^{-}$as formulated in Eqs. (9) and (10) provided the inputs required for determining the relative closeness $\left(R C_{i}\right)$ from the alternatives to the ideal solution through Eq. (11). Table 8 displays the values of $R C_{i}$ reached by each alternative, which in this context were the combinations of cities (Santander and Valencia) and years (1990, 2000 and 2006).

As with most of the indicators in Fig. 4, the values of $R C_{i}$ achieved suggested a decrease in the level of sustainability of both cities over the years. The main reason behind this situation lied in the developments experienced by Santander and Valencia throughout 
508 the 16 years covered by the time period under consideration, which resulted in a progres509 sive substitution of natural and green areas by built-up surfaces, as shown in Fig. 3. These 510 changes were negative for the achievement of most of the SDGs listed in Table 2. On the 511 one hand, the increasing presence of impermeable surfaces facilitated the occurrence of 512 urban warming, flooding, vehicle crashes and air, noise and water pollution. On the other 513 hand, these areas also hindered the generation of ecosystems, energy and food.

514 An important outcome to extract from Table 8 is related to the order of magnitude of 515 the values of $R C_{i}$ obtained, since they were very far from an ideal solution in sustainable 516 terms $\left(R C_{i}=1\right)$. This circumstance indicated that there is much room for improvement 517 in the design of urban land cover planning strategies toward the achievement of the SDGs. 518 Still, the fact that several targets and indicators in Table 1 and Table 2 are in conflict to 519 each other, in that the satisfaction of some of them results in the dissatisfaction of some 520 others, is a challenge with which urban planners and decision-makers have to deal for 521 conceiving solutions as comprehensive as possible.

522

523

524

525

526

527

528

529

530

531

532

533

534

535

536

537
Table 8. Relative closeness $\left(R C_{i}\right)$ from the degree of sustainability of Santander and Valencia over the years in terms of their surfaces to the ideal solution

\begin{tabular}{|c|c|c|}
\hline \multirow{2}{*}{ Year } & $R C_{i}$ & \\
\hline & \multicolumn{2}{|c|}{ Santander Valencia } \\
\hline 1990 & 0.451 & 0.467 \\
\hline 2000 & 0.1 & 0.460 \\
\hline 2006 & 0.373 & 0.433 \\
\hline
\end{tabular}

As a proof of potential solutions that might be implemented to enhance the sustainability of the urban skin of Santander and Valencia, a strategy consisting of replacing part of the built-up cover in both cities by urban greenspace (e.g. gardens, urban crops, green roofs or grass pavers) was proposed to retrieve the existing value of $R C_{i}$ at the beginning of the study period (1990). According to the nomenclature used by CLC project (see Table 3), this course of action was equivalent to substitute a portion of the surface corresponding to the categories 111 and 112 (continuous and discontinuous urban fabric) by 141 (green urban areas), resulting in a new fictional scenario (2006*) whose differences from 2006 are indicated in Table 9.

Table 9. Quantitative differences between the 2006 and 2006* scenarios in Santander and Valencia based on the areas covered by the CORINE Land Cover (CLC) categories 111, 112 and 141

\begin{tabular}{lrrrr}
\hline \multirow{2}{*}{ CLC } & \multicolumn{2}{l}{ Santander } & \multicolumn{3}{l}{ Valencia } \\
\cline { 2 - 5 } & \multicolumn{1}{l}{ 2006 } & 2006* & \multicolumn{1}{l}{ 2006 } & \multicolumn{1}{c}{ 2006* } \\
\hline 111 & 899.651 & 706.226 & 3366.206 & 2938.697 \\
112 & 669.455 & 525.522 & 89.117 & 77.799 \\
141 & 32.348 & 369.706 & 202.327 & 641.153 \\
\hline
\end{tabular}


Therefore, the 2006* scenario incorporated these changes into the geographic configuration of both cities in 2006, in order to increase the values of $R C_{i}$ reached that year in Santander and Valencia up to those achieved in 1990 (see Table 8). The variations required to restore the original conditions of sustainability resulted in the bar charts represented in Fig. 5, which provide a comparison of the normalized ratings per indicator for 2006 and 2006*.

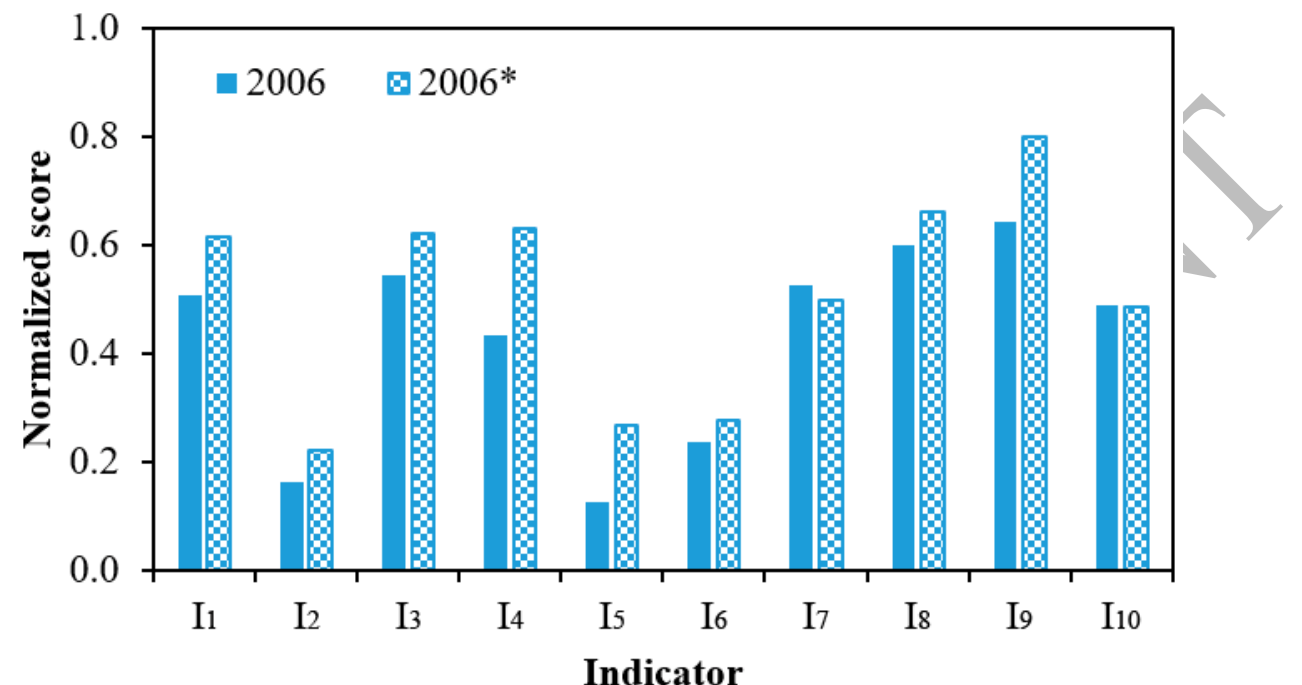

a)

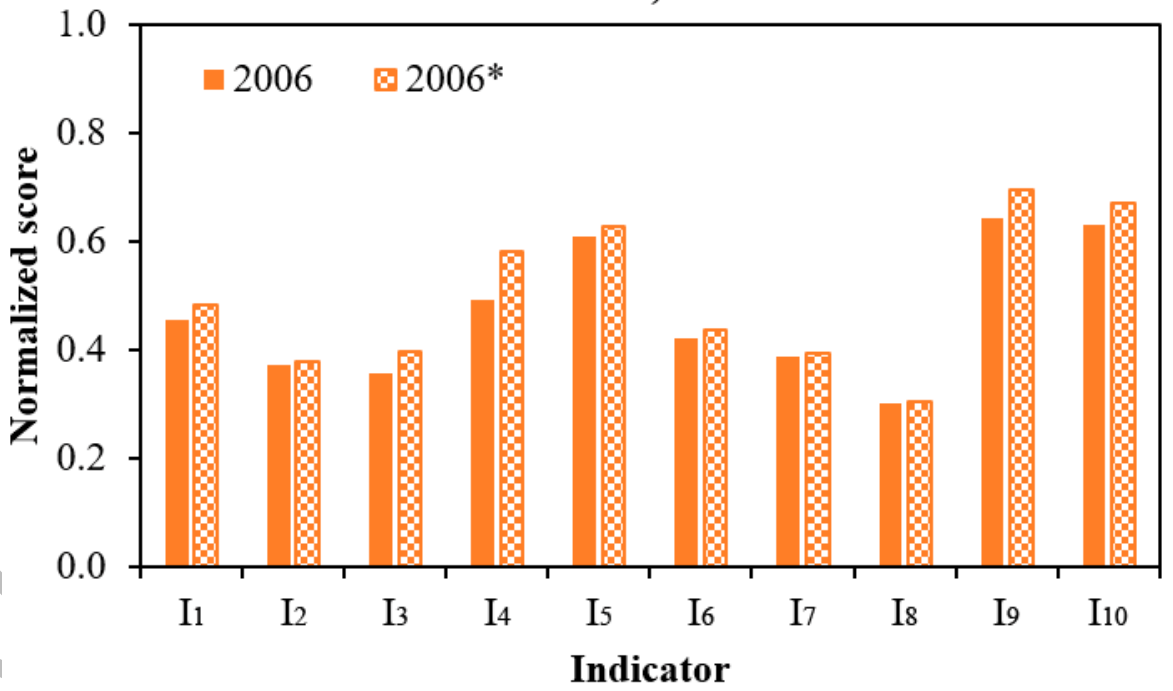

b)

Fig. 5. Normalized scores for the sustainability indicators in a) Santander b) Valencia in 2006 and in an hypothetical 2006 (2006*) in which a small portion of the built-up surface is replaced by greenspace

The proposed changes produced an improvement in the scores of all indicators except $I_{7}$, which decreased in relation to Fig. 4 due to loss of accessibility caused by the reduction in the built-up fabric. The modifications to convert the level of sustainability of the urban surfaces in Santander and Valencia in 2006 into that in 1990 required replacing 21.5\% and $12.7 \%$ of their impermeable areas by greenspace. In overall terms, these changes 
555

556

557

558

559

560

561

562

563

564

565

566

567

568

569

570

571

572

573

574

575

576

577

578

579

580

581

582

583

584

585

586

587

588

589

590

591

592

593

affected $9.4 \%$ and 3.2\% of the whole areas occupied by Santander and Valencia, respectively. The differences in the magnitude of the actions to be taken in both cities were caused by the more pronounced decrease in sustainability experienced by Santander, whose $R C_{i}$ reduction ratio doubled that determined for Valencia. Still, the amount of land cover involved in the proposed intervention strategies was limited in relation to the total surface of both cities, which proves that small and medium-scale actions for greening the skin of urban areas might have positive impacts for their sustainability

From the point of view of future urban planning and design of restoration and rehabilitation strategies, the nature of these green areas for enhancing the contribution of urban surfaces to achieving the SDGs should be strongly related to the concept of Green Infrastructure (GI). GI provide a holistic opportunity to mitigate the harmful impacts of both urbanization and Climate Change on cities. These techniques are multipurpose treatment practices capable of delivering a wide variety of benefits related to sustainable development, including temperature reduction, flood attenuation, runoff purification, carbon sequestration, job creation, food production and generation of both ecosystems and spaces for social recreation.

\section{Conclusions}

This research conceived, developed and applied a Sustainable Urban Surface Rating System (SURSIST) to measure the sustainability of the urban surfaces of an entire city through the Sustainable Development Goals (SDGs) established by the United Nations. SURSIST was founded on a combination of CORINE Land Cover (CLC) maps with the Analytic Hierarchy Process (AHP) and the Technique for Order of Preference by Similarity to Ideal Solution (TOPSIS). This framework consists of a series of measurable indicators that can be easily extrapolated across European cities, by virtue of its theoretical simplicity and the widespread availability of the data required. These indicators were selected based upon their correlation to the targets addressed by the SDGs and further characterized according to the land cover types included in the CLC project.

The results obtained through the application of SURSIST to the Spanish cities of Santander and Valencia ensured the usefulness of the proposed approach, demonstrating how the level of sustainability of the urban skin of both cities progressively decreased with time as a result of an increase in the built-up fabric, which disregarded a series of SDGs related to the protection of the environment and the responsible use of natural resources. The implementation of intervention strategies aimed at replacing part of the impermeable cover caused by human-related activities by greenspace proved to restore the degree of contribution to the SDGs provided by the urban surfaces of Santander and Valencia in 2006 to that in 1990, with moderate alterations in the whole area covered by both cities. This retrieval of the original situation was related to the fact that the presence of green 
594

595

596

597

598

599

600

601

602

603

604

605

606

607

608

609

610

611

612

613

614

615

616

617

618

619

620

621

622

623

624

625

626

627

628

629

630

631

632

633

areas benefited the sustainability indicators that contributed the most to the SDGs, which concerned flood mitigation, air and water protection and energetic efficiency.

Therefore, SURSIST provides an easy-to-use rating system to evaluate the extent to which the land cover of urban areas can help meeting the SDGs. Its application is intended to facilitate handling of the decision-making processes required to design efficient urban planning strategies to ensure the sustainability of future generations. Despite SURSIST has been tested through two case studies consisting of cities with very different demography, area and climate, future research should be devoted to applying this framework to other cities. Hence, the proposed approach might be validated and enable identifying global trends regarding the transformation of the Earth's surface provoked by human development and how this affects the accomplishment of the SDGs. Possible actions to be taken in the future should consider the implementation of Green Infrastructure (GI), since these technologies are comprehensive measures capable of attenuating the negative impacts of urbanization on the sustainability of urban surfaces by providing diverse economic, environmental and social benefits.

\section{Acknowledgments}

This paper was possible thanks to the research project SUPRIS-SUReS (Ref. BIA2015-65240-C2-1-R MINECO/FEDER, UE), financed by the Spanish Ministry of Economy and Competitiveness with funds from the State General Budget (PGE) and the European Regional Development Fund (ERDF).

\section{References}

Artetxe Arrien, A., del Hierro Cerezo, O., Pinto Tobalina, M., Gartzia Bengoetxea, N., Arias González, A., 2014. Sumideros de carbono de la Comunidad Autónoma del País Vasco - Capacidad de secuestro y medidas para su promoción, 1st ed. Servicio Central de Publicaciones del Gobierno Vasco, Vitoria (Spain).

BOE, 2016. Orden FOM/298/2016, de 15 de febrero, por la que se aprueba la norma 5.2 - IC drenaje superficial de la Instrucción de Carreteras. [WWW Document]. Off. State Gaz. URL https://www.boe.es/buscar/doc.php?id=BOE-A-2016-2405 (accessed 5.29.18).

Bretz, S.E., Akbari, H., 1997. Long-term performance of high-albedo roof coatings. Energy Build. 25, 159-167.

Buschke, F.T., 2017. Biodiversity trajectories and the time needed to achieve no net loss through averted-loss biodiversity offsets. Ecol. Modell. 352, 54-57. https://doi.org/10.1016/j.ecolmodel.2017.02.021

Caswell, S.J., Jakus, K., 1977. Role of Land Use Planning in Noise Control, in: Proceedings of the Conference on Metropolitan Physical Environment. pp. 242-253. 
634 Cervero, R., 2003. Growing smart by linking transportation and land use: Perspectives

635 from California. Built Environ. 29, 66-78. https://doi.org/10.2148/benv.29.1.66.53948

Chazarra, A., Mestre Barceló, A., Pires, V., Cunha, S., Mendes, M., Neto, J., 2011. Atlas Climático Ibérico - Iberian Climate Atlas. Agencia Estatal de Meteorología (AEMET) and Instituto de Meteorologia de Portugal, Madrid (Spain) and Lisboa (Portugal).

Coakley, J.A., 2003. Reflectance and albedo, surface, in: Holton, J.R., Curry, J.A., Pyle, J.A. (Eds.), Encyclopedia of Atmospheric Sciences. Academic Press, Cambridge, Massachusetts (U.S.), pp. 1914-1923.

644

Diaz-Sarachaga, J.M., Jato-Espino, D., Alsulami, B., Castro-Fresno, D., 2016. Evaluation of existing sustainable infrastructure rating systems for their application in developing countries. Ecol. Indic. 71. https://doi.org/10.1016/j.ecolind.2016.07.033

Diaz-Sarachaga, J.M., Jato-Espino, D., Castro-Fresno, D., 2017. Methodology for the development of a new Sustainable Infrastructure Rating System for Developing

(SIRSDEC). Environ.

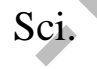

Policy

69. https://doi.org/10.1016/j.envsci.2016.12.010

651

Dobos, E., 2005. Albedo, in: Lal, R. (Ed.), Encyclopedia of Soil Science. CRC Press,

652 New York (U.S.), pp. 64-66. https://doi.org/10.1081/E-ESS 120014334

653

654

655

656

657

658

EEA, 1997. CORINE Land Cover - Technical Guide, European Environmental Agency.

ESRI, 2013. ArcGIS Desktop: Release 10.1. Environmental Systems Research Institute, Redlands, California (U.S.).

Gallagher, P.W., 2006. Energy Production with Biomass: What Are the Prospects? Choices 21(1), 21-26.

659

García-Cascales, M.S., Lamata, M.T., 2012. On rank reversal and TOPSIS method. Math. Comput. Model. 56, 123-132. https://doi.org/10.1016/j.mcm.2011.12.022

660

661

662

663

664

García-Nieto, A.P., Geijzendorffer, I.R., Baró, F., Roche, P.K., Bondeau, A., Cramer, W., 2018. Impacts of urbanization around Mediterranean cities: Changes in ecosystem service $\quad$ supply. Ecol. Indic. 91, 589-606. https://doi.org/10.1016/j.ecolind.2018.03.082

665

666

667

Ginevicius, R., Podvezko, V., 2007. Some problems of evaluating multicriteria decision methods. Int. J. Manag. Decis. Mak. 8, 527. https://doi.org/10.1504/IJMDM.2007.013415

Häkkinen, T., 2007. Assessment of indicators for sustainable urban construction. Civ.

668 Eng. Environ. Syst. 24, 247-259. https://doi.org/10.1080/10286600701315880

669

Hart, M., 2006. Guide to Sustainable Community Indicators, 2nd ed. Hart Environmental Data, North Andover, Massachusetts (U.S.).

Hassan, M.M., Nazem, M.N.I., 2016. Examination of land use/land cover changes, urban growth dynamics, and environmental sustainability in Chittagong city, Bangladesh. Environ. Dev. Sustain. 18, 697-716. https://doi.org/10.1007/s10668-015-9672-8 
674

675

676

677

678

679

680

681

682

683

684

685

686

687

688

689

690

691

692

693

694

695

696

697

698

699

700

701

702

703

704

705

706

707

708

709

710

711

712

713

Hwang, C.-L., Yoon, K., 1981. Methods for Multiple Attribute Decision Making, in: Multiple Attribute Decision Making. Lecture Notes in Economics and Mathematical Systems. Springer-Verlag, New York (U.S.), pp. 58-191. https://doi.org/10.1007/978-3-642-48318-9_3

IGN, 2017. Centro de Descargas del CNIG [WWW Document]. URL http://centrodedescargas.cnig.es/CentroDescargas/index.jsp (accessed 8.1.17).

INE, 2016. España en cifras 2016. Instituto Nacional de Estadística, Madrid (Spain).

IPCC, 2000. Land-Use, Land-Use Change, and Forestry. Cambridge University Press, Cambridge (U.K.).

Ivan, J.N., Wang, C., Bernardo, N.R., 2000. Explaining two-lane highway crash rates using land use and hourly exposure. Accid. Anal. Prev. 32, 787-795. https://doi.org/10.1016/S0001-4575(99)00132-3

Jin, G., Li, Z., Wang, Z., Chu, X., Li, Z., 2015. Impact of land-use induced changes on agricultural productivity in the Huang-Huai-Hai River Basin. Phys. Chem. Earth 7982, 86-92. https://doi.org/10.1016/j.pce.2015.01.005

Kim, K., Yamashita, E., 2002. Motor vehicle crashes andland use empirical analysis from Hawaii. Transp. Res. Rec.

King, G., Roland-Mieszkowski, M., Jason, T., Rainham, D.G., 2012. Noise levels associated with urban land use. J. Urban Heal. 89, 1017-1030. https://doi.org/10.1007/s11524-012-9721-7

Koellner, T., Scholz, R.W., 2008. Assessment of land use impacts on the natural environment: Part 2: Generic characterization factors for local species diversity in Central Europe. Int. J. Life Cycle Assess. 13, 32-48. https://doi.org/10.1065/lca2006.12.292.2

Li, X., Peterson, J., Liu, G.-J., Qian, L., 2001. Assessing regional sustainability: The case of land use and land cover change in the middle Yiluo catchment of the Yellow River Basin, China. Appl. Geogr. 21, 87-106. https://doi.org/10.1016/S01436228(00)00020-5

Lie, S.A.N., 2016. Philosophy of Nature: Rethinking naturalness, 1st ed. Routledge, London (U.K.).

Lutzenberger, A., Brillinger, M., Pott, S., 2014. Global Land-Use Analysis. Globalands $37119310,16-20$.

Machado, A., 2004. An index of naturalness. J. Nat. Conserv. 12, 95-110. https://doi.org/10.1016/j.jnc.2003.12.002

Mwavu, E.N., Witkowski, E.T.F., 2008. Land-use and cover changes (1988-2002) around Budongo Forest Reserve, NW Uganda: Implications for forest and woodland sustainability. L. Degrad. Dev. 19, 606-622. https://doi.org/10.1002/ldr.869

Olesen, J.E., Bindi, M., 2002. Consequences of climate change for European agricultural productivity, land use and policy. Eur. J. Agron. 16, 239-262. https://doi.org/10.1016/S1161-0301(02)00004-7 
714 Renetzeder, C., Schindler, S., Peterseil, J., Prinz, M.A., M † $\vdash^{-}$cher, S., Wrbka, T., 2010.

715

716

717

718

719

720

721

722

723

724

725

726

727

728

729

730

731

732

733

734

735

736

737

738

739

740

741

742

743

744

745

746

747

748

749

750

751

752

753 Can we measure ecological sustainability? Landscape pattern as an indicator for naturalness and land use intensity at regional, national and European level. Ecol. Indic. 10(1), 39-48. https://doi.org/10.1016/j.ecolind.2009.03.017

Rojas, C., Pino, J., Jaque, E., 2013. Strategic Environmental Assessment in Latin America: A methodological proposal for urban planning in the Metropolitan Area of Concepción (Chile). Land use policy 30, 519-527. https://doi.org/10.1016/j.landusepol.2012.04.018

Ross, C.W., Grunwald, S., Myers, D.B., Xiong, X., 2016. Land use, land use change and soil carbon sequestration in the St. Johns River Basin, Florida, USA. Geoderma Reg. 7(1), 19-28. https://doi.org/10.1016/j.geodrs.2015.12.001

Saaty, T.L., 1990. How to make a decision: The analytic hierarchy process. Eur. J. Oper. Res. 48, 9-26. https://doi.org/10.1016/0377-2217(90)90057-I

Sachs, J., Schmidt-Traub, G., Kroll, C., Durand-Delacre, D., Teksoz, K., 2017. SDG Index and Dashboards Report 2017. Bertelsmann Stiftung and Sustainable Development Solutions Network (SDSN), New York (U.S.).

Santos, A., Fernandes, M.R., Aguiar, F.C., Branco, M.R., Ferreira, M.T., 2018. Effects of riverine landscape changes on pollination services: A case study on the River Minho, Portugal. Ecol. Indic. 89, 656-666. https://doi.org/10.1016/j.ecolind.2018.02.036

Sepúlveda-Zúñiga, E., Parra, L.E., Benítez, H.A., Rojas-Quezada, C., 2012. State of vegetational naturalism and heterogeneity in pond wetlands and their effect on macrolepidoptera diversity (insecta: Lepidoptera). Shil. Rev. Lepidopterol. 40, 155170.

Singh, R.K., Murty, H.R., Gupta, S.K., Dikshit, A.K., 2007. Development of composite sustainability performance index for steel industry. Ecol. Indic. 7, 565-588. https://doi.org/10.1016/j.ecolind.2006.06.004

SIOSE, 2012. Manual de Metadatos de SIOSE, Sistema de Información de Ocupación del Suelo en España.

Stathopoulou, M., Cartalis, C., 2007. Daytime urban heat islands from Landsat ETM+ and Corine land cover data: An application to major cities in Greece. Sol. Energy 81, 358-368. https://doi.org/10.1016/j.solener.2006.06.014

Taha, H., 1997. Urban climates and heat islands: Albedo, evapotranspiration, and anthropogenic heat. Energy Build. 25(2), 99-103. https://doi.org/10.1016/S03787788(96)00999-1

Tucci, C.E.M., 2001. Urban drainage in specific climates. United Nations Educational, Scientific and Cultural Organization (UNESCO), Paris (France).

Tukiainen, H., Alahuhta, J., Field, R., Ala-Hulkko, T., Lampinen, R., Hjort, J., 2017. Spatial relationship between biodiversity and geodiversity across a gradient of landuse intensity in high-latitude landscapes. Landsc. Ecol. 32, 1049-1063. 
754

755

756

757

758

759

760

761

762

763

764

765

766

767

768

769

770

771

772

773

774

775

776

777

778

779

780

781

https://doi.org/10.1007/s10980-017-0508-9

UN, 2016. United Nations Conference on Housing and Sustainable Urban Development (Habitat III), in: United Nations. pp. 3-25.

UN-DESA, 2012. United Nations Conference on Sustainable Development, Rio+20 [WWW Document]. URL https://sustainabledevelopment.un.org/rio20 (accessed 8.1.17).

UN-Water, 2010. Combating waterborne disease at the household level: The International Network to Promote Household Water Treatment and Safe Storage, UN-Water Decade Programme on Advocacy and Communication (UNW-DPAC). World Health Organization, Geneva (Switzerland).

UNEP, 2012. Greening the Economy Through Life Cycle Thinking - Ten Years of the UNEP/SETAC Life Cycle Initiative, United Nations Environmental Programme.

Wang, G., Yinglan, A., Xu, Z., Zhang, S., 2014. The influence of land use patterns on water quality at multiple spatial scales in a river system. Hydrol. Process. 28, 52595272. https://doi.org/10.1002/hyp.10017

Wei, X., Hahmann, A.N., Dickinson, R.E., Yang, Z.-L., Zeng, X., Schaudt, K.J., Schaaf, C.B., Strugnell, N., 2001. Comparison of albedos computed by land surface models and evaluation against remotely sensed data. J. Geophys. Res. Atmos. 106, 2068720702. https://doi.org/10.1029/2001JD900218

Xie, D., Liu, Y., Chen, J., 2011. Mapping Urban environmental noise: A land use regression method. Environ. Sci. Technol. 45, 7358-7364. https://doi.org/10.1021/es200785x

Zhang, Q., Wallace, J., Deng, X., Seto, K.C., 2014. Central versus local states: Which matters more in affecting China's urban growth? Land use policy 38, 487-496. https://doi.org/10.1016/j.landusepol.2013.12.015

Zhou, X.-Y., Lei, K., Meng, W., 2017. An approach of habitat degradation assessment for characterization on coastal habitat conservation tendency. Sci. Total Environ. 593-594, 618-623. https://doi.org/10.1016/j.scitotenv.2017.03.212 